\title{
PADRÕES DE MARCAÇÃO POSSESSIVA EM LÍNGUAS AMERÍNDIAS: UM ESTUDO TIPOLÓGICO PRELIMINAR
}

\section{PATTERNS OF POSSESSIVE MARKING IN AMERIDIAN LANGUAGES: A PRELIMINARY TYPOLOGICAL SURVEY}

\author{
Paulo Henrique Pereira Silva de Felipe \\ Universidade Estadual de Campinas \\ Campinas, São Paulo, Brasil
}

\begin{abstract}
RESUMO: Nosso objetivo nesse trabalho tipológico é mostrar como um grupo de 39 línguas indígenas faladas ou que já foram faladas na América do Sul se comportam em relação à marcação de posse. Nesse estudo, nós mostraremos que as construções alienáveis nas línguas que apresentam diferenças formais entre as categorias de posse alienável e inalienável (Grupo A) são em sua maioria núcleo-marcadas, bem como nas construções inalienáveis, em que esse padrão foi também o mais recorrente. Nós também iremos mostrar que as línguas do Grupo A não exibem construções inalienáveis marcadas no dependente, além do fato de que os padrões de marcação de posse estão relacionados.
\end{abstract}

PALAVRAS-CHAVE: Posse Nominal; Padrões de Marcação Possessiva; Línguas Ameríndias.

ABSTRACT: The main goal of this typological survey is to show how a group of 39 indigenous languages spoken or formerly spoken in South America behave with regard to possessive marking. In this study, we show that alienable constructions in languages that display formal differences between the categories of alienable and inalienable possession (Group A) are mostly headmarked. This is also the case for inalienable constructions, where this pattern is also the most recurrent. We also show that Group A languages do not exhibit inalienable constructions marked on the dependent.

KEYWORDS: Nominal Possession; Possessive Marking Patterns; Amerindian Languages. 


\section{INTRODUÇÃO}

Neste artigo, mostramos como um conjunto de 39 línguas indígenas se comporta em relação aos padrões de marcação possessiva ${ }^{1}$. As 39 línguas analisadas neste trabalho são um recorte de uma análise maior, realizada com 90 línguas ameríndias (PEREIRA, 2016). Optamos por fazer esse recorte, e apresentar neste artigo somente as línguas do Grupo A, ou seja, aquelas que traçam formalmente distinções entre as categorias de posse alienável e inalienável, em virtude da própria natureza de um artigo científico, que exige certa brevidade na apresentação dos dados ${ }^{2}$. As línguas analisadas são faladas ou que já foram faladas em diversos países da América do $\mathrm{Sul}^{3}$. Nosso principal objetivo é verificar se há algum tipo de preferências dos idiomas por algum tipo de padrão possessivo em específico.

A seleção das línguas que compõem nosso corpus de análise levou em consideração quatro critérios: (i) distribuição geográfica: selecionamos línguas faladas nos principais países da América do Sul; (ii) diversidade filogenética: em que as línguas foram selecionadas com base na variabilidade de suas famílias linguísticas; (iii) proporcionalidade: no qual procuramos traçar uma média de línguas a serem selecionadas por família, levando em consideração o número de idiomas pertencentes a cada família linguística, e, finalmente, (iv) capacidade descritiva dos trabalhos: o que quer dizer que selecionamos as línguas cujos trabalhos de referência pudessem nos fornecer dados substanciais e confiáveis para a análise.

É importante salientar, no que tange aos critérios apresentados acima, que eles foram aplicados e se referem ao conjunto das 90 línguas que foram objeto do trabalho do qual este artigo deriva, e não somente às 39 línguas aqui apresentadas. Se tomarmos as 39 línguas isoladamente como parâmetro de aplicação desses critérios, veremos que eles não se aplicarão de forma coerente, sobretudo porque a amostra de 39 línguas não cumpre com os requisitos de cada critério. As 39 línguas, por exemplo, não representam de forma satisfatória a distribuição geográfica das línguas na América do Sul (uma vez que as outras 51 línguas analisadas como do Grupo B não foram aqui apresentadas), nem cumprem com os critérios de diversidade filogenética (só há duas línguas Tupi nesse conjunto, por exemplo, uma vez que as demais línguas foram classificadas como do grupo B e não aparecem, portanto, nesse trabalho). Em outras palavras, o que estamos dizendo é que é preciso considerar todo o conjunto analisado, ou seja, as 90

\footnotetext{
${ }^{1}$ Esses padrões serão apresentados na seção seguinte.

${ }^{2} \mathrm{O}$ trabalho completo, incluindo a análise das línguas do Grupo B (aquelas que não traçam distinções formais entre as categorias de posse) e da análise das línguas por regiões geográficas, pode ser consultado em Pereira (2016), disponível em: $<$ http://repositorio.unicamp.br/handle/REPOSIP/320924> Acesso em 02 jun. 2018.

3 A amostra de línguas selecionadas para o trabalho poderá ser vista no apêndice deste capítulo, juntamente com as abreviaturas que aparecem nas glosas dos exemplos citados no texto.
} 
línguas que foram objeto da pesquisa maior, para que esses critérios possam ser aplicados satisfatoriamente.

Além disso, é importante deixar claro que optamos por utilizar o critério de distribuição geográfica como um dos parâmetros para a seleção das línguas pois levamos em consideração a proposta de Campbell (2000) e, também, o modelo proposto por Joshua Birchall (2014). Esses autores propõem divisões para o território sul-americano, ou seja, possíveis áreas linguísticas em que as línguas estão situadas e são faladas ${ }^{4}$. Como também estamos preocupados em entender se existe alguma relação possessiva entre línguas de determinadas regiões, coletamos dados de línguas provenientes de todas essas áreas.

Escolhemos analisar as línguas sul-americanas a partir de um viés tipológico sobretudo porque há poucos trabalhos dessa natureza sendo feitos, além, é claro, da escassez de trabalhos descritivos com línguas indígenas. Acreditamos que a realização deste trabalho, que busca analisar a categoria de posse nominal em uma quantidade expressiva de línguas ameríndias, ainda que apenas os padrões de marcação possessiva, possa contribuir para o entendimento do modo como esta categoria linguística é codificada pelas línguas da América do Sul.

A fim de cumprir com esses objetivos, este artigo está dividido da seguinte forma: na seção 1, apresentamos uma breve introdução da categoria de posse nominal, bem como dos tipos de construção possessiva que analisamos neste trabalho e, na seção 2, apresentamos a análise das línguas do Grupo A, no que se refere ao modo como essas línguas traçam formalmente a diferença entre as construções alienáveis e inalienáveis, seguida da conclusão.

\section{A CATEGORIA DE POSSE NOMINAL E OS PADRÕES DE MARCAÇÃO POSSESSIVA}

É necessário apresentar, antes de iniciarmos nossa exposição dos padrões de marcação possessiva selecionados para esse trabalho, a metodologia utilizada para o tratamento dos dados das línguas da amostra. Essa metodologia, que segue à proposta por Pereira (2016), considera dois tipos principais de construção de posse: são elas: (i) construções com nomes alienáveis e (ii) construções com nomes inalienáveis.

Os nomes alienáveis dizem respeito àqueles itens que, de forma transferível ou transitória, podem ser possuídos por alguém. Esta categoria de nomes geralmente engloba o domínio de itens prototipicamente sociais, comuns,

\footnotetext{
${ }^{4}$ No apêndice, logo após a apresentação da amostra de línguas do Grupo A, apresentamos o mapa com a divisão da América do Sul adotada neste trabalho, que segue aquela proposta por Campbell (2000) e Birchall (2014). Nesse artigo, nos preocupamos em mostrar como se comportam as línguas em termos somente das marcações formais de posse. Entretanto, uma análise de como os padrões de marcação possessiva se comportam em relação a cada uma das áreas linguísticas adotadas pode ser vista em Pereira (2016, Cap. V).
} 
como itens de pesca, objetos coletivos e outros. Em (1), é possível ver exemplos de construções alienáveis:

(1) Trumai (GUIRARDELLO, 1992, pp. 101-102)

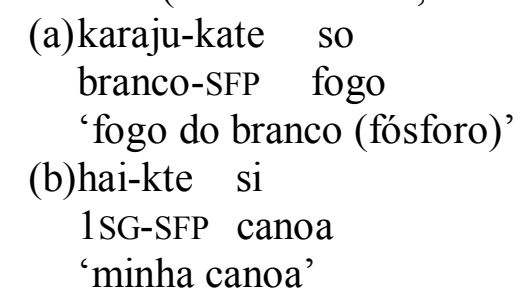

Notemos, pela construção em (1a), que temos um possuidor, representado pelo item lexical karaju, que possui um objeto, no caso um fósforo, representado no exemplo pela palavra $s o$, do Trumai. O mesmo tipo de relação possessiva pode ser visto em (1b), no qual um possuidor, representado pela primeira pessoa do singular pronominal hai, possui um item social, como é o caso de si 'canoa'. Notemos que, nestes casos, os objetos possuídos não são partes inseparáveis de seus possuidores, mas itens comumente utilizados pela comunidade em geral, razão pela qual são considerados como alienáveis em Trumai.

Diferentemente dos nomes alienáveis, os nomes inalienáveis dizem respeito àqueles itens que estão intimamente ligados aos seus possuidores. Estes itens, em virtude do tipo de relação de proximidade que estabelecem com seus proprietários, estão ligados, de acordo com Nichols (1988) aos seguintes domínios: (a) parentesco; (b) partes do corpo; (c) conceitos relacionalmente espaciais; (d) partes de outros itens; (e) estados físicos e mentais, dentre outros. Vejamos exemplos de construções inalienáveis em Kadiwéu:

(2) Kadiwéu (SANDALO, 1995, p. 59)
(a)Gonel:e:giwa 1-Geladi
homem 3sG.POSS-casa
'a casa do homem,
(b)Gad-akilo
2SG.POSS-cabeça
'sua cabeça'

Ao contrário do que vimos em (1), em (2) os itens que são possuídos estão intimamente ligados aos seus possuidores, em uma relação não transitória/transferível. ${ }^{6}$ É bem pouco provável, por exemplo, que em uma construção como "sua cabeça", conforme (2b), que o falante esteja se referindo à uma cabeça de uso social ou coletivo.

\footnotetext{
${ }^{5}$ Algumas glosas de línguas, como as do Kadiwéu, por exemplo, estavam em inglês, em virtude de o trabalho ter sido publicado no exterior. Nesses casos, fizemos uma tradução dessas glosas para o português, a fim de padronizar a leitura e o entendimento dos exemplos.

${ }^{6}$ Quando nomes inalienáveis aparecem sem um possuidor explícito, eles recebem, na maioria dos casos, um morfema que indica sua forma "não-possuída" (RICHARDS, 1973).
} 
Se considerarmos, então, que as línguas podem apresentar construções de posse com nomes alienáveis e com nomes inalienáveis, somos também obrigados a admitir que as línguas podem ou não traçar diferenças formais e semânticas entre essas categorias. Por conta desta distinção que as línguas podem exibir, que acreditamos ser um padrão importante a ser observado, é que propomos neste trabalho a divisão metodológica das línguas ameríndias em dois grandes grupos distintos, a depender dos tipos de relações possessivas que dispõem, conforme abaixo (PEREIRA, 2016):

Tabela 1. Tipos de língua (Grupos A e B).

\begin{tabular}{lll}
\hline Grupo & \multicolumn{4}{c}{ Característica } \\
\hline - Grupo A & $\begin{array}{l}\text { Representa aquelas línguas que sempre marcam } \\
\text { formalmente a oposição entre posse alienável e } \\
\text { inalienável; }\end{array}$ \\
$\begin{array}{l}\text { Representa aqueles idiomas que nunca marcam } \\
\text { formalmente a oposição entre posse alienável e } \\
\text { inalienável; }\end{array}$ \\
\hline
\end{tabular}

Fonte: (PEREIRA, 2016)

Em virtude da necessidade de síntese, nos ateremos neste artigo, como já dissemos, somente à apresentação da análise das línguas do Grupo $\mathrm{A}^{7}$. Feita, então, esta divisão, é necessário esclarecer, também, os tipos de construções de posse que estamos considerando.

Chappell e McGregor (1996) divide as construções possessivas em três tipos principais, a depender do lugar onde a marcação possessiva é expressa: (i) Construção de Posse Atributiva (doravante CPA), que são aquelas construções em que o possuidor e o item possuído formam uma espécie de sintagma possessivo (doravante SgP), como em livro do João e seu carro; (ii) Construção de Posse Predicativa, que são aquelas construções em que a relação possessiva é estabelecida por meio de um predicado, exemplo: João tem uma bicicleta ou Ele tem um bicicleta e (iii) Construção de Posse Externa, que são aqueles tipos de construções em que a relação possessiva é expressa do nível da sentença, e não propriamente dentro do SgP, como em João cortou a si mesmo no dedo (HEINE, 1997).

Neste artigo, trabalharemos somente com as Construções de Posse Atributiva, e, a exemplo do que fez Krasnoukhova (2012, p. 59), levaremos em consideração, para a análise, a comparação de quatro principais subtipos de $\mathrm{CPA},{ }^{8}$ são eles: (i) com possuidor lexical de um nome alienável (PSR LX N.AL), como em (a); (ii) com possuidor pronominal de um nome alienável (PSR PRON N.AL), como em (b); (iii) com possuidor lexical de um nome inalienável (PSR LX N.INAL), como em (c) e (iv) com possuidor pronominal de um nome inalienável (PSR PRON N.INAL), tal como em (d). Vejamos:

\footnotetext{
${ }^{7}$ Para conhecer, também, a análise das línguas do Grupo B, ver Pereira (2016, Cap. IV).

${ }^{8}$ Procuraremos apresentar cada um dos quatro subtipos de CPA nas línguas que fazem oposição entre posse alienável e inalienável.
} 
Tabela 2. Tipos de CPA.

\begin{tabular}{cll}
\hline \multicolumn{1}{c}{ Exemplo } & \multicolumn{1}{c}{ Subtipo de CPA } \\
\hline$\bullet$ "carro do Felipe/Felipe's car" & (PSR LX N.AL) \\
$\bullet$ "seu carro/his car" & (PSR PRON N.AL) \\
$\bullet$ "olhos do Felipe/Felipe's eyes" & (PSR LX N.INAL) \\
$\bullet$ "seus olhos/his eyes" & (PSR PRON N.INAL) \\
\hline
\end{tabular}

Fonte: (PEREIRA, 2016)

Os exemplos destes tipos de construções de posse nas línguas indígenas de nossa amostra podem ser vistos em (1) e (2), apresentados anteriormente, em que temos: em $(1 \mathrm{a} / \mathrm{b})$ um exemplo de CPA com PSR LX N.AL e PSR PRON N.AL, respectivamente, e, em $(2 \mathrm{a} / \mathrm{b})$, uma CPA com PSR LX N.INAL e com PSR PRON N.INAL, nesta ordem. Terminada, então, a apresentação da metodologia adotada neste trabalho, partiremos, agora, para a apresentação dos padrões de marcação possessiva.

Os padrões de marcação possessiva dizem respeito, basicamente, ao lugar de imersão do marcador de posse (se no possuidor ou no possuído). Com base na comparação linguística, Nichols $(1988,1992)$ defende que a identificação do lugar ocupado pelo marcador de posse constitui um parâmetro suficiente para que se determine a distribuição das oposições alienável/inalienável. De acordo com ela, partindo do critério formal, há apenas dois lugares em que se pode situar o marcador de posse: (i) no núcleo possuído, que geralmente ocorre em forma de afixo possessivo, e constitui o padrão núcleo-marcado (NM) ou (ii) no dependente, que pode ser um nome ou pronome possuidor, caso em que, tipicamente, ocorre em forma de um caso chamado genitivo ou possessivo e constitui o padrão dependente-marcado (DM). Há, ainda, duas outras possibilidades de marcação de posse: (iii) por dupla-marcação (DLM) e (iv) por ausência de marcação (ØM). Estes quatro padrões podem ser esboçados da seguinte maneira:

Tabela 3. Padrões de marcação de posse

\begin{tabular}{ll}
\hline & $\begin{array}{l}\text { Núcleo-marcado: o núcleo (possuído) da CPA é marcado } \\
\text { morfologicamente; }\end{array}$ \\
$>$ & $\begin{array}{l}\text { Dependente-marcado: o possuidor (dependente) } \\
\text { morfologicamente marcado; }\end{array}$ \\
$>$ & $\begin{array}{l}\text { Dupla-marcação: tanto o dependente quanto o núcleo são marcados } \\
\text { morfologicamente; }\end{array}$ \\
$>$ & Ausência de marcação $($ ØM): nenhum dos membros é marcado.
\end{tabular}

Fonte: (PEREIRA, 2016)

A seguir, é possível ver exemplos desses quatro tipos de padrões. Um exemplo de língua de NM é dado (3), em que um prefixo é anexado ao possuído, enquanto um exemplo de DM é dado em (4), em que o item lexical recebe um 
sufixo de posse (SFP). Notemos, ainda, que na sentença em (3), um prefixo que indica, além de posse, número e pessoa, é anexado ao núcleo possuído. Temos, neste caso, um prefixo possessivo pessoal.

(3) Navarro (MORGAN, 1980 apud HEINE, 1997)
(a) ashkii bi-deezhí menino 3SG-jovem irmã
'A irmã mais nova do menino'

(4) Awa Pit (CURNOW, 1997)
(a) Santos-pa pimpul
Santos-SFP perna
'a perna do Santos' abaixo:

Os exemplos de línguas de DLM e ØM, por seu turno, podem ser vistos

Huallaga (WEBER, 1983)
(a) Juan-pa wasi-n
Juan-SFP casa-3SG.POSS
'casa do Juan'

(6) (6) Atakapa (SWANTON, 1929, p. 126)

(a) ha tal

ele pele

'pele dele'

Esta oposição entre a marcação nuclear e a que recai sobre o dependente é um dos mais importantes parâmetros na análise das construções possessivas, segundo Nichols (1986). Isto porque, segundo a autora, os padrões núcleo vs. dependente-marcado são traços genéticos estruturalmente estáveis, o que quer dizer que é altamente provável que eles sejam inerentes às línguas e não fruto de empréstimos linguísticos. Veremos na seção seguinte a análise destes padrões nas línguas do Grupo A.

\section{ANÁLISE DOS DADOS}

\section{1 línguas do Grupo A}

Como as línguas desse grupo traçam distinções formais entre as categorias de posse, optamos por apresentar, primeiramente, o modo como se dão os padrões de marcação possessiva em construções alienáveis, e, depois, nas construções inalienáveis. A divisão entre posse alienável e inalienável não apenas representa a cisão que estas línguas fazem, em termos formais, entre as categorias de posse, mas também tem caráter didático, já que nos ajudará a perceber as diferenças entre um tipo e outro de construção possessiva. 


\subsubsection{A posse alienável}

Das 39 línguas que compõem o Grupo A, 27 são núcleo-marcadas em construções alienáveis. Vejamos alguns exemplos:

(7) Kadiwéu (SANDALO, 1995, pp. 58-59)
(a)Pedro l-n-aqi:di
Peter 3SG.POSS-POSS.AL-rio
'o rio do Peter'
(b)Gad:-n-aqi:di
2SG.POSS-POSS.AL-rio
'seu rio'

(8) Toba (MESSINEO, 2003, pp. 128-132)
(a) da Bernardo ni la-magaso
CTC Bernardo CTC 3SG.POSS-calças
'as calças de Bernardo'
(b)i-n-ado?o
1SG.POSS-POSS.AL-chapéu
'meu chapéu'

Das 12 línguas restantes, 10 marcam morfologicamente a posse no dependente, ou seja, são línguas de padrão dependente-marcado. Vejamos um exemplo:

(9) Hup (EPPS, 2005, p. 195)
(a)tiñ̃h
hõp kək cúk tinñ̄ mŭh, tinĩh kapí? b’ŏk
3SG-SFP pesca puxar vara 3SG-SFP fecha 3SG-SFP caapi pote
'Sua vara de pesca, sua flecha, seu pote de caapi'

As outras 2 línguas restantes desenvolveram outros tipos de estratégias possessivas, tais como a dupla-marcação, como em (10), ou, ainda, por simples justaposição, sem nenhum tipo de marcação morfológica, como em (11).

(10) Aguaruna (CORBERA MORI, 1994, p. 128)
(a)ámi-na kutfi-nú-m
2SG-SFP porco-POSS.AL-2SG.POSS
'Teu porco'

(11) Tariana (AIKHENVALD, 2003, p. 483)
(a)t finu panisi
cachorro casa
'casa do cachorro'

A tabela 4, a seguir, sintetiza, em termos numéricos, essas informações: 
Tabela 4. Valores relativos aos Padrões de Marcação de Posse Alienável

\begin{tabular}{lcc}
\hline \multicolumn{1}{c}{ Padrão } & $N^{o}$ de Línguas & Porcentagem \\
\hline Núcleo-marcado (NM) & 27 línguas & $69,23 \%$ \\
Dependente-marcado (DM) & 10 línguas & $25,64 \%$ \\
Dupla-marcação (DLM) & 1 língua & $2,56 \%$ \\
Ausência de Marcação (ØM) & 1 língua & $2,56 \%$ \\
\hline Total: & 39 línguas & $99,99=100 \%$ \\
\hline
\end{tabular}

Fonte: (PEREIRA, 2016)

Diante deste quadro, é também possível traçar a seguinte hierarquia, em termos de frequência, para os padrões de marcação de posse alienável nas línguas do Grupo A:

(Grupo A): núcleo-marcado $\rightarrow$ dependente-marcado $\rightarrow \longrightarrow$ ausência de marcação

Em o padrão mais recorrente nas línguas de nossa amostra é o núcleomarcado, seguido pelo dependente-marcado e pelos padrões ausência de marcação e dupla-marcação.

\subsubsection{A posse inalienável}

Nas construções com nomes inalienáveis, o padrão núcleo-marcado também é o mais recorrente: das 39 línguas da amostra, 33 apresentam construções deste tipo. Vejamos alguns exemplos:

(12) Kadiwéu (SANDALO, 1995, p. 59)
(a) Gad-akilo
2SG.POSS-cabeça
'sua cabeça'
(b)Gonel:e:giwa 1-Geladi
homem 3SG.POSS-casa
'a casa do homem'

O segundo padrão mais recorrente nas construções com nomes inalienáveis é a ausência de marcação, que dispõe de 5 idiomas, a saber: Barasano, Desano, Dâw, Hup e Wắnsöjöt. Exemplos do Hup são apresentados a seguir:

(13) Hup (EPPS, 2005, pp. 201-202)
(a) Pắh-Pín
1SG-mãe
'minha mãe'
(b)tã Pắy-Píp w’ŏt
mulher-pai alta
'a mulher do pai é alta' 
No que tange ao padrão dupla-marcação, por sua vez, somente a língua Aguaruna, de toda nossa amostra, marca posse inalienável em ambos os membros da construção possessiva. É possível conferir esse tipo de padrão pelos exemplos em (14), abaixo:

(14) Aguaruna (CORBERA MORI, 1994, p. 129; OVERALL, 2007, p. 137)
(a)ámi-na buuki-m
2SG-SFP cabeça-2SG.POSS
'tua cabeça'
(a)duhi waã-hĩ
nariz-SFP buraco-1PL.POSS
'narina' (lit. buraco da narina)

Vimos, pelos exemplos apresentados anteriormente, que as línguas do Grupo A, quando em construções inalienáveis, podem marcam posse tanto no núcleo (núcleo-marcado), quanto no núcleo e no dependente (dupla-marcação), ou, ainda, não marcar em nenhum dos membros (ausência de marcação), como vimos pelos exemplos das línguas sem marcação morfológica. O que é surpreendente, entretanto, é que diferentemente do que ocorreu nas construções alienáveis, nas construções com nomes inalienáveis não houve línguas que marcassem posse no dependente, isto é, que manifestassem unicamente o padrão dependente-marcado. Esse tipo de conclusão nos leva a concordar com Nichols (1988), uma vez que a autora acredita que a inalienabilidade está intimamente relacionada com o padrão núcleo-marcado, enquanto a alienabilidade está com o dependente-marcado. abaixo:

Os dados que justificam esta hierarquia podem ser vistos na tabela 19,

Tabela 5. Valores relativos aos Padrões de Marcação de Posse Inalienável

\begin{tabular}{lcc}
\hline \multicolumn{1}{c}{ Padrão } & $N^{o}$ de Linguas & Porcentagem \\
\hline Núcleo-marcado (NM) & 33 línguas & $84,61 \%$ \\
Ausência de Marcação (ØM) & 5 línguas & $12,82 \%$ \\
Dupla-marcação (DLM) & 1 língua & $2,56 \%$ \\
Dependente-marcado (DM) & Nenhuma & $0 \%$ \\
\hline Total: & 39 línguas & $99,99=100 \%$ \\
\hline
\end{tabular}

Fonte: (PEREIRA, 2016)

A hierarquia dos padrões de marcação de posse nas construções inalienáveis obedece, assim, a seguinte lógica:

(Grupo A): núcleo-marcado $\rightarrow$ ausência de marcação $\rightarrow$ dupla marcação $\rightarrow$ dependente-marcado (não encontrado nas línguas de nossa amostra do Grupo A).

É pertinente notarmos, pelos dados apresentados até aqui, que tanto nas construções de posse com nomes alienáveis quanto nas inalienáveis o padrão núcleo-marcado é o mais recorrente. Isto nos leva a postular que, embora as 
línguas do Grupo A tracem diferenças entre posse alienável e inalienável, as marcações de posse obedecem, em sua maioria, ao mesmo padrão. Os valores apresentados acima podem ser melhor visualizados em termos do gráfico seguinte, no qual os percentuais referentes à posse são resumidos.

Gráfico 1. Valores relativos aos Padrões de Marcação de Posse (Grupo A)

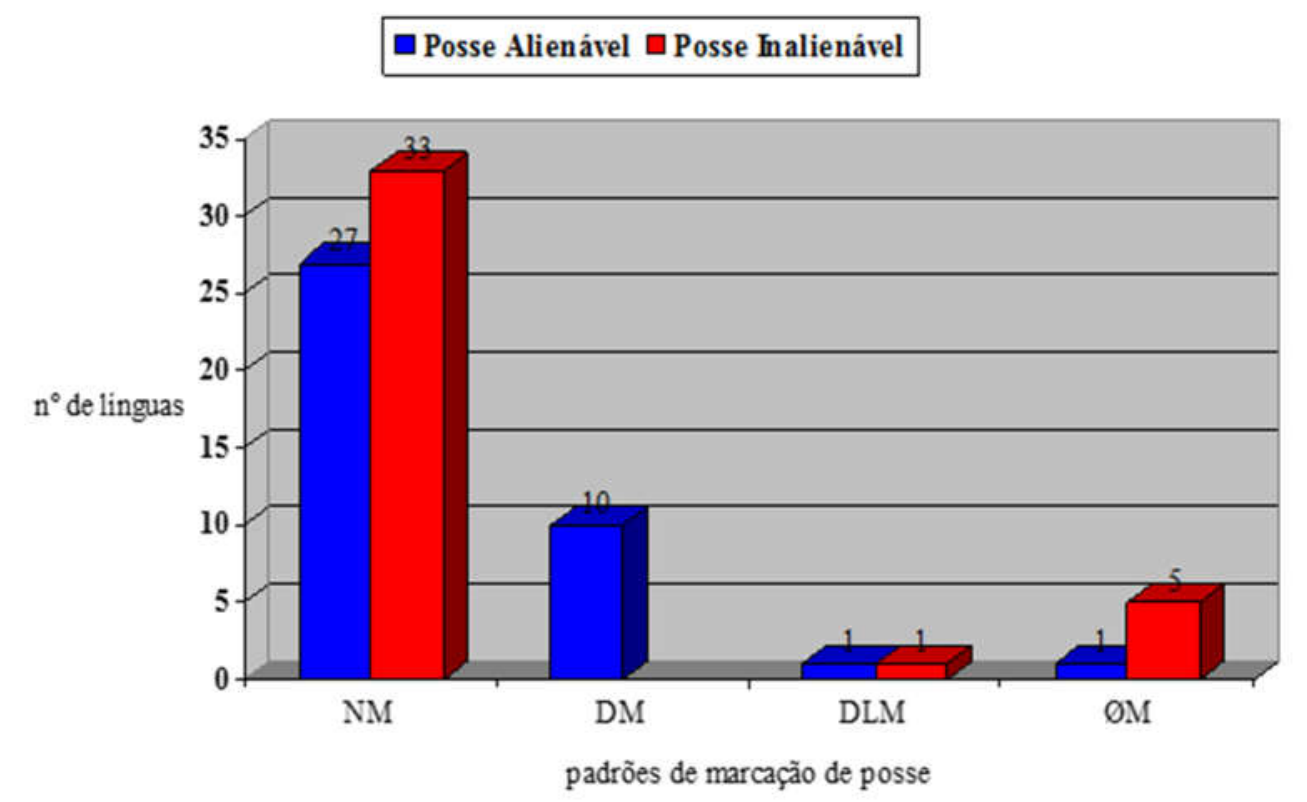

Fonte: (PEREIRA, 2016)

\subsubsection{Outras observações a respeito dos padrões de marcação de posse}

Além das observações levantadas acima, outras podem ser somadas à análise da categoria de posse nominal nas línguas da amostra. A primeira dessas observações diz respeito às correlações que podem ser feitas entre os padrões de marcação de posse nos idiomas analisados. Em Desano, Barasano, WắnsöjötPuinave, Hup, Dâw, Wichí, Nivaclé, Trumai, Karo e Jarawara, por exemplo, há uma correlação entre o padrão de marcação possessivo das construções alienáveis e aquele das construções inalienáveis, ou seja, enquanto nas construções alienáveis o padrão destas línguas é dependente-marcado, nas inalienáveis o padrão é ausência de marcação.

É claro, todavia, que algumas dessas línguas, como Wichí, Nivaclé, Trumai, Karo e Jarawara, além de marcar posse inalienável por justaposição (padrão ausência de marcação) dos membros do sintagma de posse, também podem marcar no núcleo quando o possuidor for lexical ${ }^{9}$. Como, entretanto, estes idiomas também marcam posse por justaposição, como em Desano, Barasano, Wắnsöjöt-Puinave, Hup e Dâw, em que este é o único recurso marcador de posse inalienável ${ }^{10}$, acreditamos que a marcação por justaposição em construções

\footnotetext{
${ }^{9} \mathrm{O}$ que estamos dizendo, aqui, é quem nem sempre as línguas da amostra marcam posse somente de uma forma.

${ }^{10}$ No momento de contabilizar as línguas cujo padrão é ausência de marcação, levamos em consideração, como pode ser visto na seção 2.1.2 acima, somente aqueles idiomas
} 
inalienáveis seja uma característica das línguas cujas construções alienáveis são dependente-marcadas.

Krasnoukhova (2012, p. 90) propõe, para as línguas com construções alienáveis dependente-marcadas, três padrões gerais para a marcação de construções inalienáveis: (a) a posse inalienável é marcada sistematicamente no dependente, tanto com possuidor pronominal quanto com lexical; (b) a posse inalienável é não-marcada, tanto com possuidor lexical quanto com possuidor pronominal e (c) a posse inalienável pode se tornar núcleo-marcada, mas apenas com possuidor pronominal.

$\mathrm{O}$ primeiro destes padrões não se aplica às línguas do Grupo $\mathrm{A}$, ou seja, aquelas que traçam distinções formais entre as categorias de posse alienável e inalienável, uma vez que, como vimos, não há exemplos de línguas dependentemarcadas em construções inalienáveis ${ }^{11}$.

$\mathrm{O}$ segundo destes padrões, por outro lado, refere- se às línguas Desano, Barasano, Wắnsöjöt-Puinave, Hup, e Dâw, citadas acima, que, como dissemos, marcam posse inalienável, seja com possuidor lexical ou pronominal, apenas por justaposição, o que constitui o padrão ausência de marcação. Vejamos exemplos de duas dessas línguas:

(15) Hup (EPPS, 2005, pp. 201-202)

(a) Rắh-?ín

1SG-mãe

'minha mãe'

(b)tã Pấy-Píp w’ǒt

mulher-pai alta

'a mulher do pai é alta'

(15) Dâw (MARTINS, 2004, p. 546)

(a)tih nũh

3SG cabeça

'cabeça dele'

(b) drw juì

Dâw sangue

'sangue do Dâw'

Por fim, o último destes padrões defendidos por Krasnoukhova (2012) refere-se, por sua vez, às línguas Wichí, Nivaclé, Trumai, Karo e Jarawara, cujas

em que este padrão é o único disponível. As línguas que marcam posse por ausência de marcação, mas que também marcam de outras formas (no núcleo, por exemplo), só o fazem em condições especial, como quando em construções com possuidores lexicais. Neste caso, não consideramos essas línguas como verdadeiros casos de ausência de marcação, motivo pelo qual somente 5 línguas (Desano, Barasano, Wắnsöjöt-Puinave, Hup e Dâw), foram consideradas deste tipo na seção 2.1.2, dedicada às construções de posse inalienável.

${ }^{11}$ Mas se aplica às línguas do Grupo B. Para saber mais sobre o Grupo B, ver Pereira (2016). 
construções de posse inalienável são núcleo-marcadas com possuidores pronominais e não-marcadas com possuidores lexicais.

Este tipo de correlação não ocorre entre os outros padrões de posse. Assim, línguas que são núcleo-marcadas em construções alienáveis tendem a ser, também, núcleo-marcadas em construções inalienáveis. O que podemos encontrar, nestes idiomas, é uma possibilidade de marcação por justaposição quando o possuidor for lexical. Não encontramos nenhuma língua, contudo, em que a posse alienável obedecesse ao padrão núcleo-marcado e a inalienável a outro padrão.

O mesmo ocorre com as línguas duplamente marcadas, como o Aguaruna, em que tanto as construções alienáveis quanto as inalienáveis obedecem ao padrão dupla-marcação. A língua Tariana, única que marca posse por justaposição em construções alienáveis, marca posse inalienável preferencialmente no núcleo e por justaposição quando o possuidor for pronominal.

A Tabela 6, abaixo, resume as correlações entre os padrões de posse encontrados. O parêntese que circunda o padrão indica que ele também ocorre, mas com menos frequência ou em condições específicas, como é o caso da marcação de posse inalienável por justaposição apenas com possuidores lexicais:

Tabela 6. Correlações entre os padrões de marcação de posse

\begin{tabular}{|c|c|c|c|c|}
\hline \multirow{4}{*}{$\begin{array}{l}\text { Posse } \\
\text { Alienável }\end{array}$} & (i) & $\mathrm{DM}$ & ØM/ (NM) & \multirow{4}{*}{$\begin{array}{r}\text { Posse } \\
\text { Inalienável }\end{array}$} \\
\hline & (ii) & NM & $\mathrm{NM} /(Ø \mathrm{Q})$ & \\
\hline & (iii) & DLM & DLM & \\
\hline & (iv) & Øм & $\mathrm{NM} /(\varnothing \mathrm{M})$ & \\
\hline
\end{tabular}

Fonte: (PEREIRA, 2016)

A partir da observação da Tabela 6, acima, é possível depreender: (i) que as línguas que traçam distinções formais entre a categoria de posse alienável e inalienável (Grupo A), tendem a ser não-marcadas em construções inalienáveis quando a construção alienável for dependente-marcada; (ii) que as línguas núcleo-marcadas em construções alienáveis tendem a ser também núcleomarcadas em construções inalienáveis (com exceção do possuidor lexical que pode aparecer justaposto ao item possuído); (iii) que as línguas duplamente marcadas em construções alienáveis são também duplamente marcadas em construções inalienáveis e (iv) que as línguas não-marcadas para a posse alienável tendem a ser núcleo-marcadas em construções inalienáveis (com exceção do possuidor lexical, que pode aparecer justaposto ao item possuído).

A observação desses dados nos possibilita depreender, portanto, que a marcas formais de posse nas línguas de nossa amostra estão concentradas, majoritariamente, ou no possuidor ou no possuído o que, em nossos termos, constitui os padrões dependente-marcado e núcleo-marcado, respectivamente. Tomando como referência a Tabela 6 , acima, ilustramos, na Tabela 7, abaixo, a quantidade de línguas que se relacionam, no que tange aos padrões possessivos: 
Tabela 7. Número de línguas cujos padrões de marcação de posse se correlacionam

\begin{tabular}{lrr}
\hline Posse Alienável & Posse Inalienável & \multicolumn{1}{c}{$N^{o}$ de línguas } \\
\cline { 2 - 3 } DM & $\emptyset \mathrm{M} /(\mathrm{NM})$ & $10 /(5)$ \\
$\mathrm{NM}$ & $\mathrm{NM} /(\varnothing \mathrm{M})$ & $27 /(24)$ \\
$\mathrm{DLM}$ & $\mathrm{DLM}$ & 1 \\
$\varnothing \mathrm{M}$ & $\mathrm{NM} /(\varnothing \mathrm{M})$ & $1(1)$ \\
\hline Total & & 39 línguas \\
\hline
\end{tabular}

Fonte: (PEREIRA, 2016)

O parêntese que circunda o número indica que tais línguas manifestam mais de uma forma de marcação de posse, ou seja, mais de um padrão possessivo em contextos específicos. É o caso, por exemplo, das construções de posse inalienável nos idiomas Wichí, Nivaclé, Trumai, Karo e Jarawara que, como já vimos, podem ser tanto não-marcadas quanto núcleo-marcadas, quando a construção alienável for dependente-marcada.

\section{ALGUMAS CONSIDERAÇÕES PRELIMINARES}

Vimos, ao longo da exposição do trabalho, que as línguas se comportam de formas variadas no que se refere à categoria de posse nominal. Dentre as conclusões preliminares possíveis, vimos que: (i) as construções alienáveis nas línguas deste grupo são, em sua maioria, NM, bem como as construções inalienáveis, onde este padrão foi também o mais recorrente; (ii) as línguas do Grupo A não apresentam construções inalienáveis marcadas no dependente; (iii) os padrões de marcação de posse podem se correlacionar, de modo que línguas que marcam posse no dependente em construções alienáveis tendem a ser nãomarcadas em construções inalienáveis, por exemplo; (iv) as línguas de DM em construções alienáveis tendem a apresentar os mesmos tipos de marcação de posse, seja nas construções com possuidores lexicais ou pronominais, ao passo que as de NM não e, ainda, (v) que a língua Tariana é a única da amostra do Grupo A que apresenta construções alienáveis com menos material morfológico que nas construções inalienáveis

Esperamos, nesse artigo, ter fornecido um panorama geral a respeito dos padrões de marcação possessiva nas línguas indígenas da América do Sul, bem como ter contribuído, embora muito brevemente, para um melhor entendimento das relações possessivas, em especial da posse nominal, nos idiomas analisados.

\section{REFERÊNCIAS}

AIKHENVALD, Alexandra e DIXON, Robert Malcolm Ward. The amazonian languages. Cambridge: Cambridge University Press, 1999. 
AIKHENVALD, Alexandra. "Areal diffusion, genetic inheritance, and problems of subgrouping: a north arawak case study". In: AIKHENVALD, Alexandra e DIXON, Robert Malcolm Ward. (orgs.). Areal diffusion and genetic inheritance. Oxford: Oxford University Press, pp. 167-194, 2001.

AIKHENVALD, Alexandra. Language contact in amazonia. Oxford: Oxford University Press, 2002.

. A grammar of tariana. Cambridge: Cambridge University Press, 2003.

CAMPBELL, Lily. "On so-called pan-americanisms". In: International Journal of American Linguistics 57 (3), 1991, p. 394-399.

. American Indian languages: the historical linguistics of native America.

Oxford: Oxford University Press, 2000.

. "Classification of the indigenous languages of South America". In: CAMPBELL, Lily e GRONDONA, Veronica. (org.). The indigenous languages of South America: a comprehensive guide. Berlin: Mouton de Gruyter, pp. 259330, 2012a.

CHAPPELL, Hilary e McGREGOR, William. Alienability, inalienability and nominal classifications. Proceedings of the fifteenth annual meeting of the Berkeley Linguistics Society, 1989, p. 24-36.

. The grammar of inalienability: a typological perspective on body part terms and the part-whole relation. Berlin: Mounton de Gruyster, 1996a.

"Prolegomena to a theory of inalienabilty". In: CHAPPELL, Hilary e McGREGOR, William. The grammar of inalienability: a typological perspective on body part terms and the part-whole relation. Berlim: Mounton de Gruyster, 1996b, p. 3-30.

CORBERA MORI, Angel Humberto. Fonologia e Gramática do Aguaruna (Jívaro). 1994. 395f. Tese (doutorado), Universidade Estadual de Campinas.

. "A posse nominal em línguas Arawak do sul e Arawak central: uma abordagem descritiva". In: Estudos Lingüísticos XXXIV, 2005, p. 263-268.

. "Aspectos da morfofonologia e morfologia nominal da língua Mehinaku (Arawak)". In: FRANCHETTO, Bruna. Alto Xingu: uma sociedade multilingue. Rio de Janeiro: Museu do Î́ndio- FUNAI, 2011.

CURNOW, Timothy Jowan. A grammar of Awa Pit (Cuaiquier): An indigenous language of south-western Colombia. The Australia Nacional University, 1997.

DIXON, Robert Malcolm Ward. The Jarawara language of southern Amazonia. Oxford: Oxford University Press, 2004a. 
EPPS, Patience. A Grammar of Hup. Tese de doutorado. University of Virginia. Charlottesville, Virginia; 2005.

GUIRARDELLO, Raquel. Aspectos da Morfossintaxe da Língua Trumai (isolada) e de seu sistema de marcação de caso. Dissertação de mestrado. Universidade Estadual de Campinas (UNICAMP). Campinas (SP), 1992.

GUIRARDELLO, Raquel. Trumai reference grammar. Ph.D. dissertation, Rice University, 1999.

HASPELMATH, Martin. Alienable vs. inalienable possessive constructions. Max Planck Institute for Evolutionary Anthropology. Leipzig: Spring School on Linguistic Diversity, 2014.

HEINE, Bernd. Possession: cognitive sources, forces and grammaticalization. Cambridge: Cambridge University Press, 1997.

KAUFMAN, Terrence. "Language history in South America: what we know and how to know more". In: PAYNE, David L. (org.). Amazonian linguistics: studies in lowland South American languages. Texas Linguistics Series. Austin: University of Texas Press, 1990, p. 13-78.

KRASNOUKHOVA, Olga. "Attributive possession in the languages of South America". In: Linguistics in the Netherlands (28), 2011, p. 86-98.

. The noun phrase in the languages of South America. Doctoral dissertation. Radboud: Universiteit Nijmegen, 2012.

MARTINS, Silvana Andrade. Fonologia e Gramática Dâw. Vrije Universiteit. Holanda. Tese de doutorado, 2004.

MESSINEO, Cristina. Lengua toba (guaycurú). Aspectos gramaticales y discursivos. Munich: Lincom Europa, 2003.

McGREGOR, William. "Introduction". In: McGREGOR, William (org.). The expression of possession. Berlim: Mouton de Gruyter, 2008, p. 1-12.

NICHOLS, Johanna. Head-marking and dependent-marking grammar. Language (62/56), 1986, p. 119.

. "On alienable and inalienable possession". In: SHIPLEY, William (org.). In honor of Mary Haas. Berlim: Mouton de Gruyter, 1988, p. 475-521.

OVERALL, Simon E. A Grammar of Aguaruna. La Trobe University. Australia, 2007.

PEREIRA, Paulo Henrique da Silva. Aspectos morfossintáticos da marcação de posse nominal em línguas ameríndias. Dissertação de Mestrado em Linguística. Universidade Estadual de Campinas (UNICAMP), 2016. 
RODRIGUES, Aryon Dall'Igna. Línguas brasileiras: para entender as línguas indigenas brasileiras. São Paulo: Loyola, 2002.

. "Sobre as línguas indígenas e sua pesquisa no Brasil". IN: Cienc.

Cult., vol. 57, $\mathrm{n}^{\mathrm{o}}$ 2, São Paulo, 2015. Disponível em: $<$ http://cienciaecultura.bvs.br/scielo.php?pid=S000967252005000200018\&script=sci ar ttext $>$ Acesso em 28 jan. 2015

SAKEL, Jeanette. A grammar of mosetén. Berlim: Mouton de Gruyter, 2004.

SANDALO, Filomena. A Grammar of Kadiwéu. University of Pittsburgh. Pittsburgh. Ph.D. dissertation, 1995.

SEILER, Hansjakob. "Possessivity, subject and object". Studies in Language (7), 1983a, p. 89-177.

SEKI, Lucy. "A linguística indígena no Brasil". IN: Delta, vol. 15, n. esp, 1999, p. $257-290$.

TAYLOR, John. Possessive genitives in English. Linguistics (27), 1989, p. 663686.

WEBER, David John. A Grammar of Huallaga (Huanuco) Quechua. University of California, 1983.

\section{ABREVIATURAS}

AL 'alienável'; ART 'artigo'; DEM 'demonstrativo'; INAL 'inalienável'; LX 'lexical'; M 'masculino'; N 'nome'; NE 'neutro'; PFP.PESS 'prefixo possessivo pessoal'; PL 'plural'; PONT 'pontual'; POSS 'possessivo'; PRON 'pronome/al'; PSD 'possuído'; PSR 'possuidor'; PST 'passado'; REAL 'real'; REL 'relacional'; REM 'remoto'; SFP 'sufixo possessivo'; SG 'singular'; T 'tempo'; 1 ' $1^{\mathrm{a}}$ pessoa'; 2 ' $2^{\mathrm{a}}$ pessoa'; 3 ' $3^{\mathrm{a}}$ pessoa'.

\section{APÊNDICE}

\section{Amostra de línguas do Grupo A}

A seguir, apresentamos as 39 línguas que compõem nossa amostra do Grupo A. 
Tabela 8: Amostra de línguas de grupo A

\begin{tabular}{|c|c|c|c|c|}
\hline & Autor & Ano & Língua/Família & País \\
\hline 1 & R. M. Dixon & 2004 & Jarawara/Arawá & Brasil \\
\hline 2 & Sidney Facundes & 2000 & Apurinã/Arawak & Brasil \\
\hline 3 & Elena Mihas & 2010 & Asheninka/Arawak & Peru \\
\hline 4 & Álvarez e Socorro & 2002 & Baniwa/Arawak & Venezuela \\
\hline 5 & Swintha Danielson & 2007 & Bauré/Arawak & Bolívia \\
\hline 6 & Kenneth Swift & 1988 & Caquinte/Arawak & Peru \\
\hline 7 & Ilda de Souza & 2008 & Kinikinau/Arawak & Brasil \\
\hline \multirow[t]{2}{*}{8} & Tânia Granadillo & 2004 & Kurripako/Arawak & Venezuela \\
\hline & Tânia Granadillo & 2006 & Kurripako/Arawak & Venezuela \\
\hline 9 & Angel Corbera Mori & 2011 & Mehinaku/Arawak & Brasil \\
\hline 10 & Glauber Silva & 2013 & Paresi-Haliti/Arawak & Brasil \\
\hline 11 & A. Aikhenvald & 2003 & Tariana/Arawak & Brasil \\
\hline 12 & G. Nascimento & 2012 & Terena/Arawak & Brasil \\
\hline 13 & Manoel Santos & 2006 & Wapixana/Arawak & Brasil \\
\hline 14 & Joan Richards & 1973 & Waurá/Arawak & Brasil \\
\hline 15 & Mitzila Mujica & 1992 & Yawalapiti/Arawak & Brasil \\
\hline 16 & Filomena Sandalo & 1995 & Kadiwéu/Guaikuru & Brasil \\
\hline 17 & Verónica Grondona & 1998 & Mocoví/Guaikuru & Argentina \\
\hline 18 & Cristina Messineo & 2003 & Toba/Guaikuru & Argentina \\
\hline \multirow[t]{2}{*}{19} & Raquel Guirardello & 1992 & Trumai/Isolada & Brasil \\
\hline & Raquel Guirardello & 1999 & Trumai/Isolada & Brasil \\
\hline 20 & Sinval Souza Filho & 2007 & Akwẽ-Xerente/Jê & Brasil \\
\hline 21 & Christiane Oliveira & 2005 & Apinajé/Jê & Brasil \\
\hline 22 & Rosane Sá Amado & 2004 & Gavião-Pykobjê/Jê & Brasil \\
\hline 23 & Maxwell Miranda & 2010 & Krahô/Jê & Brasil \\
\hline 24 & Maria Reis Silva & 2001 & Mebengokrê/Jê & Brasil \\
\hline 25 & Luciana Dourado & 2001 & Panará/Jê & Brasil \\
\hline 26 & Marília Ferreira & 2003 & Parkatejê/Jê & Brasil \\
\hline 27 & Flávia Castro Alves & 2004 & Timbira/Jê & Brasil \\
\hline 28 & Marília F. Borges & 1996 & Kayapó/Jê & Brasil \\
\hline 29 & Carlo S. O. Campos & 2009 & Maxakalí/Jê & Brasil \\
\hline \multirow[t]{2}{*}{30} & Angel Corbera Mori & 1994 & Aguaruna/Jívaro & Peru \\
\hline & Simon E. Overall & 2007 & Aguaruna/Jívaro & Peru \\
\hline 31 & Alain Fabre & 2014 & Nivaclé/Mataco-Mataguaio & Argentina/Paraguai \\
\hline 32 & Jimena Terraza & 2009 & Wichí/Mataco-Mataguaio & Argentina \\
\hline 33 & Silvana Martins & 2004 & Dâw/Nadahup $^{12}$ & Brasil \\
\hline 34 & Patience Epps & 2005 & Hup/Nadahup & Colômbia \\
\hline 35 & Jesús Girón Higuita & 2008 & Wắnsöjöt/Nadahup & Colômbia \\
\hline 36 & W. Jones e P. Jones & 1991 & Barasano/Tukano & Colômbia \\
\hline 37 & Marion Miller & 1999 & Desano/Tukano & Brasil \\
\hline 38 & Cristina C. Borella & 2000 & Aweti/Tupi & Brasil \\
\hline 39 & Nilson Gabas Junior & 1999 & Karo/Tupi & Brasil \\
\hline
\end{tabular}

Fonte: (PEREIRA, 2016)

\footnotetext{
${ }^{12}$ As línguas da família Nadahup também são conhecidas tradicionalmente como Maku. Como, todavia, este termo tem sido considerado pejorativo por alguns autores, optamos por utilizar o termo Nadahup, a exemplo do que propõe Epps (2008).
} 
2. Mapa da divisão do continente em áreas linguísticas

Mapa 1: Mapa da divisão do continente em áreas linguísticas

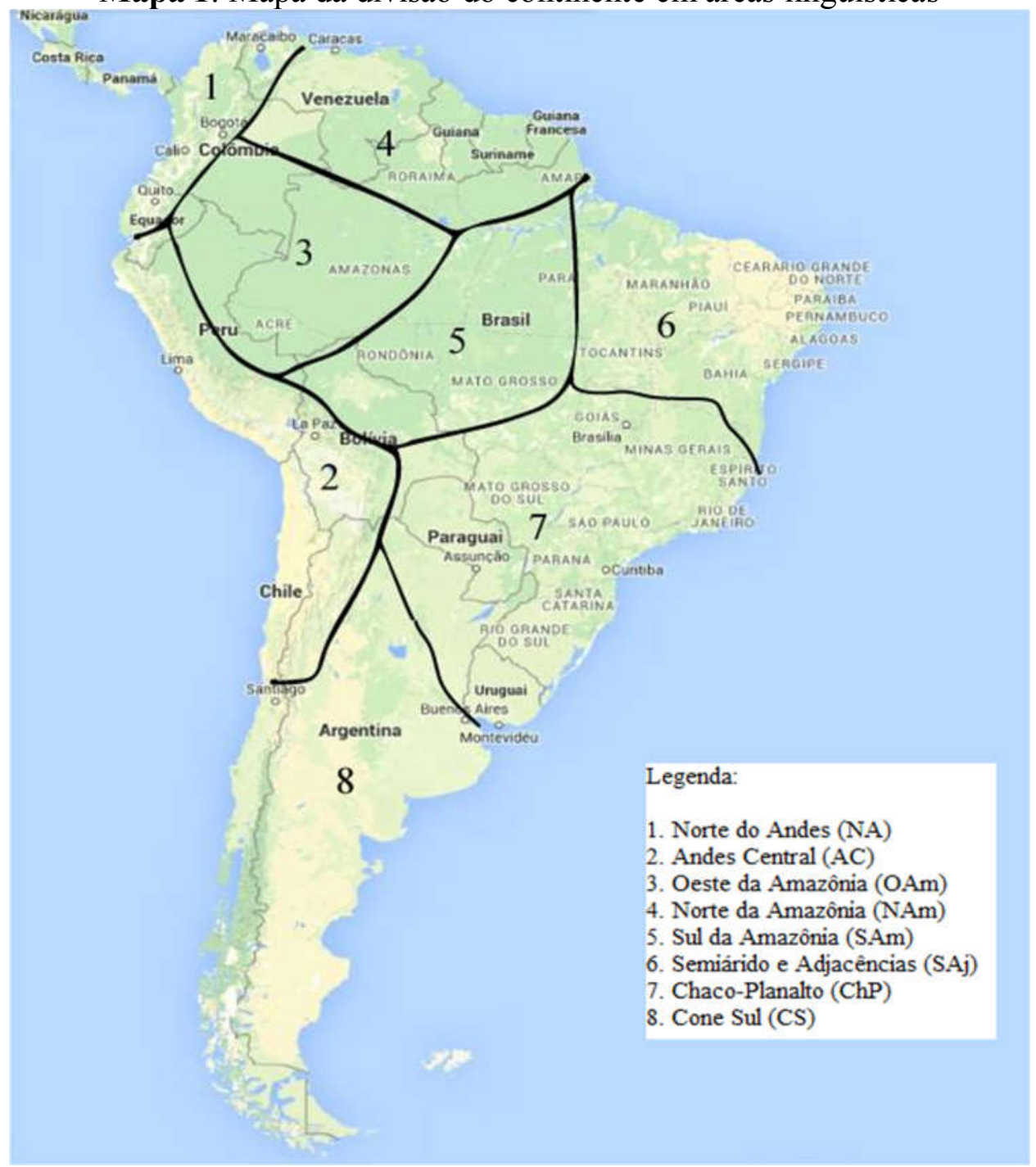

Fonte: (PEREIRA, 2016)

Paulo Henrique Pereira Silva de Felipe PauloH2SP@gmail.com

Recebido em: 5 fev. 2018

Aceito em: 11 jun. 2018

Publicado em: 19 ago. 2018 